\title{
Plasma-activated water: a new and effective alternative for duodenoscope reprocessing
}

This article was published in the following Dove Press journal:

Infection and Drug Resistance

\author{
Gheorghe G Bălan' \\ Irina Roșca ${ }^{2}$ \\ Elena-Laura Ursu² \\ Florica Doroftei ${ }^{2}$ \\ Andra-Cristina Bostănaru ${ }^{3}$ \\ Eugen Hnatiuc ${ }^{4}$ \\ Valentin Năstasă ${ }^{3}$ \\ Vasile Șandru ${ }^{5}$ \\ Gabriela Ștefănescu' \\ Anca Trifan' \\ Mihai Mareș \\ 'Grigore T. Popa University of \\ Medicine and Pharmacy, lași, \\ Romania; 2"Petru Poni” Institute \\ of Macromolecular Chemistry, lași, \\ Romania; ${ }^{3}$ Ion lonescu de la Brad \\ University of Agricultural Sciences \\ and Veterinary Medicine of lasi, \\ lași, Romania; "“Gheorghe Asachi" \\ Technical University, Iași, Romania; \\ ${ }^{5}$ Department of Gastroenterology \\ Research, Clinical Emergency Hospital \\ of Bucharest, Bucharest, Romania
}

Correspondence: Irina Roșca Centre of Advanced Research in Bionanoconjugates and Biopolymers (IntelCentru), "Petru Poni" Institute of Macromolecular Chemistry, 4IA Grigore Ghica Voda Alley, 700487 lași, Romania

$\mathrm{Tel}+40232217454$

Fax +4023221 1299

Email rosca.irina@icmpp.ro
Introduction: Duodenoscopes have been widely used for both diagnostic and therapeutic endoscopic retrograde cholangiopancreatography procedures. Numerous outbreaks of duodenoscopeassociated infections involving multidrug-resistant bacteria have recently been reported. Plasma activated water (PAW) has been widely considered an effective agent for surface decontamination and is increasingly used for disinfection of medical equipment. The aim of this study was to evaluate whether the duodenoscopes currently on market are suited for the repeated use of PAW and to test the efficacy of PAW for their disinfection.

Materials and methods: In order to evaluate the disinfection efficacy and the required time of contact, the duodenoscope samples were contaminated by immersing them in fasted-state simulated intestinal fluid containing Escherichia coli, Klebsiella pneumoniae, Acinetobacter baumannii, and Pseudomonas aeruginosa, prior to PAW exposure. In order to test the duodenoscope polymer compatibility with PAW, a challenge test was conducted by immersing the samples in PAW for 30 minutes daily for 45 consecutive days.

Results: Significant reductions in bacterial populations were achieved after 30 minutes of PAW treatment, indicating a high-level disinfection. Atomic force microscopy and scanning electron microscopy were used to demonstrate that repeated PAW treatment of duodenoscope coating polymer samples did not result in significant differences in morphological surface between the treated and untreated samples. Energy-dispersive X-ray spectroscopy analysis also showed no significant differences between the elemental composition of the duodenoscope coating polymer samples before and after repeated PAW treatment.

Conclusion: Considering these preliminary results, PAW could be considered as a new alternative for duodenoscope reprocessing.

Keywords: PAW, antibacterial activity, duodenoscope, disinfection

\section{Introduction}

Emergence of multi- and pan-drug resistance in nosocomial digestive endoscopyassociated infections is becoming a big concern. ${ }^{1}$ Most nosocomial pathogens can persist on duodenoscope surfaces for weeks or even months, ${ }^{2}$ and the safety of highlevel disinfection of duodenoscope surfaces for controlling nosocomial duodenoscopetransmitted pathogens has been a continuous debate for some time. Duodenoscopes are specially designed upper digestive tract endoscopes, which are widely used for both diagnostic and therapeutic endoscopic retrograde cholangiopancreatography (ERCP) procedures. According to the Spaulding classification of medical devices, reprocessing duodenoscope needs to be consistent with high-level disinfection. ${ }^{3}$ During the last years, numerous outbreaks of duodenoscope-associated transmission of multidrug-resistant 
bacteria have been reported worldwide. ${ }^{1,4,5}$ Staphylococcus aureus, Klebsiella pneumoniae, Enterococcus faecalis, Escherichia coli, and Pseudomonas aeruginosa are the bacteria most frequently reported to cause contaminations and duodenoscope-transmitted infections, especially because of their ability to form biofilms.

Duodenoscope reprocessing standards include either high-level disinfection or sterilization in accordance with the manufacturer's and guideline recommendations. ${ }^{6,7}$ Due to their complex design, duodenoscopes may not be suited for proper high-level disinfection using the current reprocessing standards. Finding solutions to this issue represents a hot topic in current research.

Nonthermal plasma discharge has recently been widely acknowledged as an effective method for decontamination and is increasingly proposed for biomedical sterilization of various types of equipment. ${ }^{8-12}$ Nonthermal plasma proved its valuable properties in surface reprocessing due to its high efficiency in destroying microorganisms causing minimal or no damage to the solid substrates involved. ${ }^{13-15}$ Plasmaactivated water (PAW) is highly active against a large panel of germs, is easy to use, and has the ability to kill microorganisms that otherwise cannot be destroyed by nonthermal plasma discharges (i.e., areas of a device that are not directly exposed or difficult to reach). ${ }^{16}$

Within this context, the aim of our study was to evaluate whether duodenoscopes and their surface components are suited for repeated use of PAW in reprocessing cycles. We also aimed to evaluate the efficacy of PAW in high-level disinfection of endoscopy unit in order to consider PAW as a possible new alternative for duodenoscope reprocessing. To our knowledge, this is the first study using PAW for duodenoscope reprocessing. PAW was previously reported as an important disinfectant, but its effect was evaluated only in vitro against planktonic bacteria or biofilms, not directly on medical devices.

\section{Materials and methods Duodenoscope samples}

In order to assess the potential of high-level disinfection activity of PAW and its impact on duodenoscope resin surfaces, we selected a duodenoscope (TJF-160F; Olympus Corporation, Tokyo, Japan) from a high-volume tertiary hospital that was previously used in up to 500 ERCP and duodenoscopy procedures between 2012 and 2014. The model of duodenoscope we selected for our study has been successfully and extensively used around the world in numerous highvolume centers in the same period, and is regarded as one of the best operating duodenoscopes available on the market.
It was dismantled, and samples from the outer resin polymer coating measuring $1 \mathrm{~cm}^{2}$ each were taken for analysis.

We performed two types of experiments: one for the evaluation of the disinfectant properties of PAW in biomimetic conditions and one for the evaluation of PAW compatibility with duodenoscope polymer resins.

\section{PAW preparation}

PAW was prepared using distilled water and a GlidArc reactor as previously described. ${ }^{16}$ Briefly, the plasma generator was supplied with an AC high-voltage transformer (an output voltage of $10 \mathrm{kV}$ and a maximum output current of $100 \mathrm{~mA}$ ); the gliding arc discharge operated at an industrial frequency of $50 \mathrm{~Hz}$ and used air as gas carrier at a flow rate of $40 \mathrm{~L} / \mathrm{min}$. The average value of the discharge power was 111.6 W. A volume of $300 \mathrm{~mL}$ distilled water was exposed to the plasma discharge for 10 minutes.

The final physicochemical parameters of PAW were as follows: conductivity $446 \pm 25 \mu \mathrm{S} / \mathrm{cm}, \mathrm{pH} 2.78 \pm 0.12$, oxydation reduction potential (ORP) $+1.06 \mathrm{~V}, \mathrm{NO}_{2}^{-} 192 \pm$ $10 \mathrm{mg} / \mathrm{L}, \mathrm{NO}_{3}{ }^{-} 1550 \pm 95 \mathrm{mg} / \mathrm{L}, \mathrm{H}_{2} \mathrm{O}_{2} 2.6 \pm 0.12 \mathrm{mg} / \mathrm{L}$, and $\mathrm{O}_{3} 1.08 \pm 0.07 \mathrm{mg} / \mathrm{L}$.

\section{PAW disinfectant activity evaluation in biomimetic conditions}

Four types of strains, namely Acinetobacter baumannii ATCC 19606, E. coli ATCC 25922, P. aeruginosa CIP 82118, and $K$. pneumoniae CIP 53153, were used to evaluate the disinfectant properties of PAW. The coating polymer samples were contaminated in a bacterial suspension and exposed to PAW at various periods $(5,10,15,20$, and 30 minutes, respectively). Each experiment was done in triplicate, and uncontaminated controls were used each time.

Ten milliliters of standardized bacterial suspension in normal saline solution $\left(10^{8} \mathrm{cfu} / \mathrm{mL}\right)$ was mixed with $90 \mathrm{~mL}$ of fasted-state simulated intestinal fluid ${ }^{17}$ (Table 1), in order to

Table I Fasted-state simulated intestinal fluid

\begin{tabular}{ll}
\hline Composition & Units \\
\hline Sodium taurocholate $(\mathrm{mM})$ & 3 \\
Lecithin $(\mathrm{mM})$ & 0.2 \\
Maleic acid $(\mathrm{mM})$ & 19.12 \\
Sodium hydroxide $(\mathrm{mM})$ & 34.8 \\
Sodium chloride $(\mathrm{mM})$ & 68.62 \\
Mucin $(\mathrm{g} / \mathrm{L})$ & 1 \\
\hline Properties & Units \\
\hline pH & 6.5 \\
Osmolality $(\mathrm{mOsm} / \mathrm{kg})$ & $180 \pm 10$ \\
Buffer capacity $(\mathrm{mmol} / \mathrm{L} / \mathrm{pH})$ & 10 \\
\hline
\end{tabular}


reproduce the organism's physiological conditions, and then the solution was vortexed. Duodenoscope coating polymer samples were maintained in this environment for 15 minutes with continuous stirring to create friction between surface and simulated environment at $37^{\circ} \mathrm{C}$ in order to create biomimetic conditions. After 15 minutes of incubation, the samples were removed, left for 1 minute to dry, and afterwards immersed separately in $20 \mathrm{~mL}$ of fresh PAW and maintained for 5, 10, 15, 20, and 30 minutes under periodic stirring. The samples were then removed and left for 1 minute to dry. Once dried, all samples were transferred to bottles containing $30 \mathrm{~mL}$ of sterile tryptic soy broth, and afterwards they were air-sealed and incubated at $36 \pm 1^{\circ} \mathrm{C}$ for 72 hours. The presence of turbidity after incubation indicated bacterial growth, signifying the presence of viable microorganisms on the samples after disinfection, while the absence of turbidity after incubation indicated the lack of viable microorganisms and the disinfectant efficacy of PAW for the given time of contact. In order to confirm the absence of viable bacteria, all the incubated bottles, regardless of the media appearance, were checked by subculturing on proper solid media. The absence of turbidity (clear medium) and negative subcultures were consistent with high-level disinfection of samples. In order to avoid contamination with other microbial species, all procedures were performed in a microbiological safety cabinet class II.

\section{PAW compatibility with duodenoscope polymer resins}

To assess the impact of repeated PAW treatment on duodenoscope polymer structure, a challenge test was performed. The samples were immersed in PAW for 30 minutes daily, for a 45-day period. The controls were treated similarly, but distilled water was used instead of PAW. All the samples (treated with PAW and untreated) were analyzed by scanning electron microscopy (SEM), atomic force microscopy (AFM), and energy-dispersive X-ray spectroscopy (EDX).

The images collected from the surface of duodenoscope samples and controls were recorded in air, in tapping mode, using NTEGRA Spectra (NT-MDT, Moscow, Russia) instru- ment with 3.1-37.6 N/m force constant cantilever of a silicon nitride cantilever (NSC10; NT-MDT). The roughness average values for the controls and PAW-treated samples were determined from three AFM images (scanned surface $10 \times$ $10 \mu \mathrm{m}$ ) using free data analysis software Gwyddion (version 2.20, http://gwyddion.net/).

The surface morphology of the controls and treated samples was investigated using a scanning electron microscope (Quanta200; FEI Company, Hillsboro, OR, USA) at $20 \mathrm{kV}$ with low-vacuum secondary electron (LFD) detector. In order to obtain the elemental information, EDX analysis using a silicon drift detector was performed on both controls and samples.

\section{Results}

The antimicrobial activity was evaluated against four types of strains, that is, E. coli, K. pneumoniae, A. baumannii, and $P$. aeruginosa. After 20 minutes of treatment, the initial burden drastically reduced for $E$. coli and A. baumannii only, as these were compatible with a high level of disinfection. After 30 minutes of contact with PAW, complete inactivation occurred in all the tested bacterial strains. This fact was confirmed by the complete absence of microbial growth on subcultures (compatible with high-level disinfection) (Table 2).

Significant reduction in all bacterial strains was achieved after 30 minutes of PAW contact, proving the effectiveness of this new approach in duodenoscope reprocessing.

Figures 1 and 2 show the AFM and SEM topographic images of the untreated and PAW-treated samples, respectively. The untreated duodenoscope samples were characterized by an inhomogeneous morphology and appearance of micro-cracks. After PAW treatment, no remarkable changes occurred in the morphology of the duodenoscope samples compared with the original surfaces. The roughness average value for controls was $28.46 \mathrm{~nm}$, while for the treated samples was $25.63 \mathrm{~nm}$, suggesting no changes in the surface structure of the duodenoscope after PAW treatment.

EDX analysis was used to determine the differences in the elemental composition between untreated control and treated

Table 2 PAW antimicrobial activity

\begin{tabular}{lllll}
\hline Tested strain & $\mathbf{5}$ minutes & I0 minutes & I5 minutes & $\mathbf{2 0}$ minutes \\
\hline Escherichia coli & + & + & + & - \\
Klebsiella pneumoniae & + & + & + & - \\
Acinetobacter baumannii & + & + & + & - \\
Pseudomonas aeruginosa & + & + & + & - \\
\hline
\end{tabular}

Note: + indicates the presence of turbidity in the culture media (microbial growth); - indicates no turbidity (confirmed by complete absence of growth on subcultures, that is, high-level disinfection).

Abbreviation: PAW, plasma-activated water. 

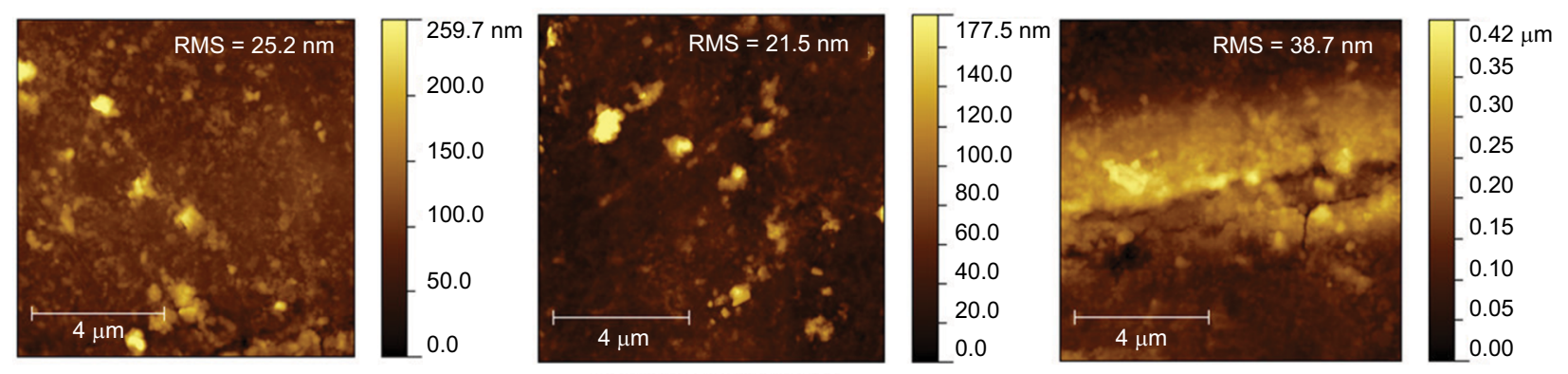

Untreated surfaces
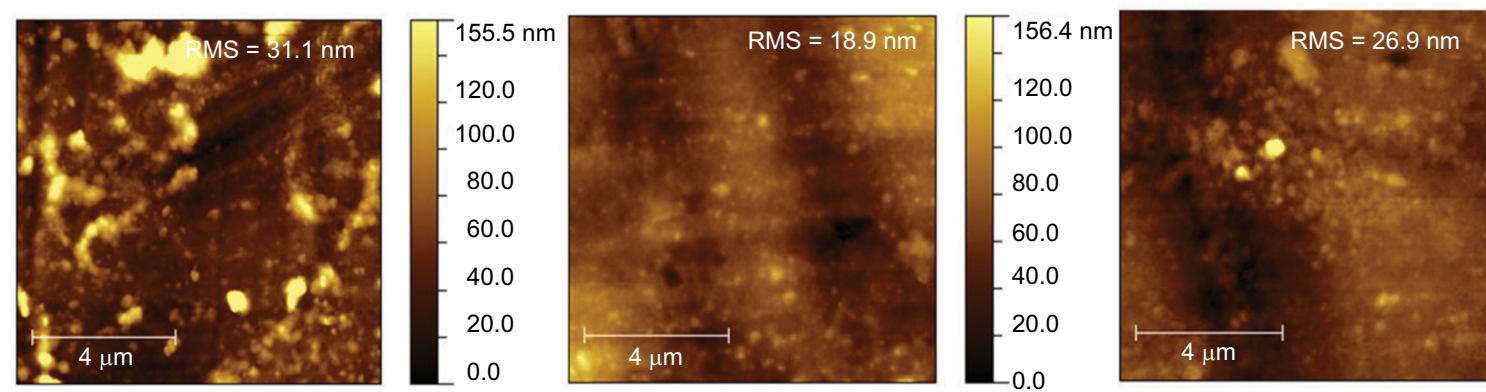

$202.6 \mathrm{~nm}$

150.0

100.0

50.0

PAW-treated surfaces

Figure I AFM topographic images of the untreated and PAW-treated samples.

Abbreviations: AFM, atomic force microscopy; PAW, plasma-activated water; RMS, root mean square.
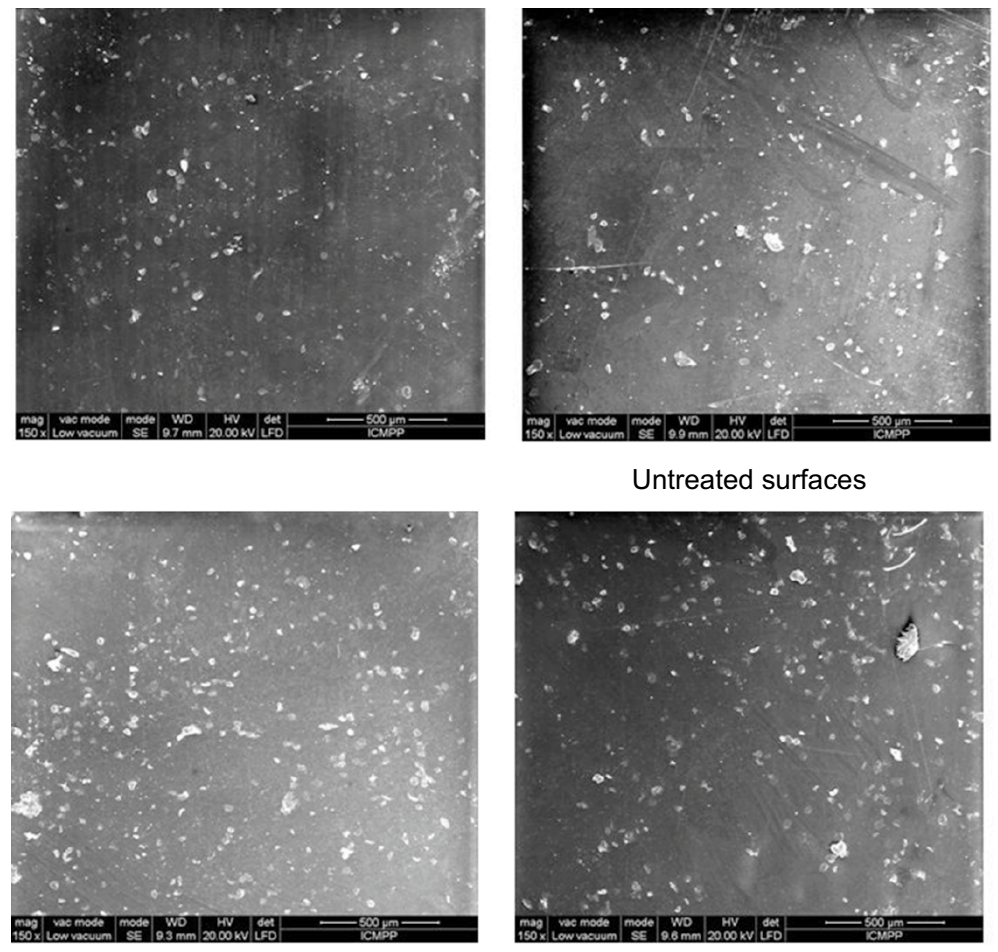

Untreated surfaces

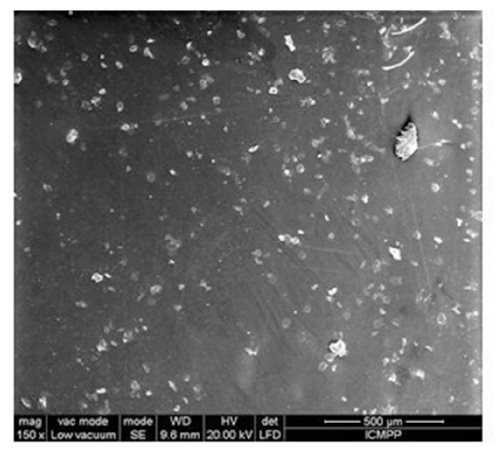

PAW-treated surfaces
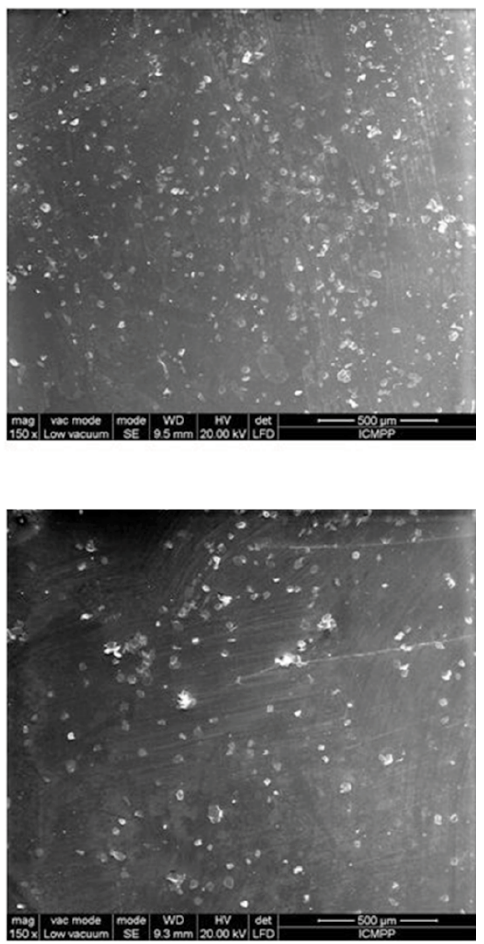

Figure 2 SEM micrographs of duodenoscope samples before and after PAW treatment.

Abbreviations: SEM, scanning electron microscopy; PAW, plasma-activated water. 
Table 3 Elemental composition of the duodenoscope surface for the controls and treated samples

\begin{tabular}{lll}
\hline Element & Controls, At $\%$ & Samples, At\% \\
\hline $\mathrm{C}$ & 83.40 & 83.36 \\
$\mathrm{~N}$ & 03.84 & 04.37 \\
$\mathrm{O}$ & 12.30 & 12.03 \\
$\mathrm{Na}$ & 00.09 & 00.05 \\
$\mathrm{Mg}$ & 00.03 & 00.01 \\
$\mathrm{Al}$ & 00.05 & 00.02 \\
$\mathrm{P}$ & 00.03 & 00.02 \\
$\mathrm{~S}$ & 00.20 & 00.13 \\
$\mathrm{~K}$ & 00.07 & 00.02 \\
\hline
\end{tabular}

samples. The results proved no significant differences in the composition between the two types of samples (Table 3).

\section{Discussion}

While sterilization can be defined as the process leading to complete absence of any type of viable contaminating microorganism, as stated by the US FDA, high-level disinfection is a reprocessing method that aims to inactivate a large amount of microorganisms (such as bacteria, viruses, or fungi) - at least 6-log to 9-log reduction of the duodenoscope bioburden which is compatible with its use in ERCP. ${ }^{18,19}$ Therefore, using PAW as a high-level disinfection agent could be a feasible alternative.

Plasma discharge in water generates highly reactive components such as oxygen ions, hydrogen and hydroxyl ions, peroxide, hydrogen peroxide, singlet oxygen, and nitric oxides, primarily in the form of radicals. The treated water is "activated" acquiring new physical, chemical, and biological properties, the most important being the remarkable antimicrobial capacity, as it was proven by our results shown in Table 2. In case of activated water, there is also a "post-discharge" antimicrobial effect manifested until a few days after discontinuation of plasma discharge in water due to both interaction of reactive species with the water ${ }^{20}$ and changes inherent to it (changes in the supramolecular structure of water, becoming mostly monomolecular; changes in the energy status of the water visible through considerable change of the absorption spectra; lowering of the $\mathrm{pH}$; and redox potential change). Adding this physical molecular effect to a reprocessing substance resolves the most distressing issue related to duodenoscope high-level disinfection, namely the inaccessibility of many duodenoscope parts to the physical removal of biofilm and bioburden traditionally done by brushing under a chemically active solution followed by high-level disinfection. ${ }^{7}$ PAW ensures physical removal of biofilm and bioburden through simple contact of activated water with the duodenoscope's most inaccessible areas.

Many Gram-negative species isolated from patients with nosocomial infections, such as Acinetobacter spp., E. coli, Klebsiella spp., P. aeruginosa, Serratia marcescens, or Shigella spp., can survive on inanimate surfaces even for months. Gram-negative bacteria persist longer than Gram-positive bacteria, especially in humid conditions. ${ }^{21-23}$ Persistence of clinically relevant bacteria on dry inanimate surfaces ranges between 3 days and 5 months for Acinetobacter spp., 1.5 hours and 16 months for E. coli, 2 hours and 30 months for Klebsiella spp., and 6 hours and 16 months for Pseudomonas spp. ${ }^{24}$

Therefore, the antimicrobial activity of PAW was evaluated in our study on four bacterial species that are usually involved in ERCP procedure-related infections: E. coli, $K$. pneumoniae, A. baumannii, and P. aeruginosa. Consequently, we need to acknowledge that viruses do not develop resistance to any type of reprocessing method, as they are easily inactivated during the pre-cleaning or manual washing of duodenoscopes. ${ }^{25,26}$ With regard to fungi, traditionally it has been stated that even if fungal contamination of duodenoscopes may occur, proper inactivation and decontamination is achieved through usual bactericidal reprocessing methods. ${ }^{27,28}$ Nevertheless, although a possible downside, activity of PAW against endospores was not tested, as exposure to resistant endospores is often achieved over extended exposure times that are not feasible in clinical practice..$^{5}$ Moreover, there are no protocols related to the inactivation of viruses, parasites, or fungi on duodenoscopes during high-level disinfection, and in such circumstances, the presence of mesophilic bacteria is used as an indicator for improper reprocessing. ${ }^{5}$

Bacterial peritonitis with $E$. coli was detected a long time ago after left-sided endoscopy was performed on a patient ${ }^{29}$ as a singular case. During the last years, several duodenoscoperelated infections have been reported in the literature. In 2013, 32 patients were found to harbor one or two clonal strains of a multidrug-resistant strain. ${ }^{30}$ Duodenoscope-related nosocomial infections due to $K$. pneumoniae have also been detected in two French hospitals. ${ }^{31}$ Also, in 2012, serial outbreaks of carbapenem-resistant Enterobacteriaceae (CRE) and other multidrug-resistant organism infections had emerged. ${ }^{32-34} \mathrm{In}$ 2015, a hospital in California announced that 179 patients were possibly exposed to CRE, seven patients were infected, and death of two patients was a result of CRE infection. ${ }^{35} \mathrm{In}$ 2010, in Netherlands, duodenoscope-related infections with multidrug-resistant $P$. aeruginosa were reported. ${ }^{36}$ Our results showed that PAW has $100 \%$ double-controlled bactericidal 
effect after 30 minutes of exposure, proving promising properties as a disinfectant for duodenoscope in terms of efficiency, time consumption, and financial aspects.

Usually, the coating materials of duodenoscopes - resin polymers - are heat labile and require disinfection with chemical agents or low-temperature sterilization methods in order to achieve high-level disinfection. The disinfecting agents used for high-level disinfection of duodenoscope can be classified into the following groups: high-level (glutaraldehyde, peracetic acid, ethylene oxide), intermediate-level (ethanol, formaldehyde, phenolic solutions) which do not have sporicidal activity, and low-level (povidone-iodine, cetrimide, benzalkonium chloride) which do not destroy Mycobacterium tuberculosis, atypical mycobacteria, and bacterial spores. ${ }^{3,6}$ Through their repeated daily use on duodenoscopes, the high-level disinfectants are associated with alterations of duodenoscope resin polymers, despite the low-temperature disinfection process, either by forming fissures in the duodenoscope surface or by affecting its elasticity parameters. ${ }^{37}$ The pre-disinfection procedures are believed to contribute to these alterations too. ${ }^{38,39}$ Such results are consistent with our previous findings according to which routine day-to-day usage of duodenoscopes is associated with microfissures, scratches, and increased porosity of the polymer resins mainly secondary to duodenoscope handling and hard-surface contacts during the reprocessing cycles. ${ }^{40}$

After repeated PAW treatment of the duodenoscope, no remarkable changes in the micro-morphology and elemental composition occurred when compared with the original surfaces, proving that PAW could be safely used as a highlevel disinfectant with biomedical applications. Such results have not been to date described in the literature. Moreover, high-level disinfection by PAW shortens the overall duration of a reprocessing cycle and makes the duodenoscopes less likely to suffer structural damage secondary to hard-surface friction. Overall, with its bactericidal and anti-biofilm effects alongside with excellent safety in what the duodenoscopestructure is concerned, PAW can be considered as a potent high-level disinfectant for duodenoscope reprocessing.

\section{Conclusion}

Our preliminary study showed several aspects characterized by novelty and usefulness. PAW reprocessing is characterized by significant decrease of bacterial populations, doubled by no surface and composition damage of the duodenoscope polymer resin. It allows skipping the water-rinsing stage of disinfection and minimizes biofilm formation. Therefore, PAW could be considered as a new and effective alternative method of disinfection for duodenoscope reprocessing, to be used after current-standard manual cleaning. Nevertheless, although promising, such results should be confirmed through case-control tests with current reprocessing standard methods, and also by including other duodenoscope models in order to assess the efficacy of the system.

\section{Acknowledgment}

This project received funding from the European Union's Horizon 2020 research and innovation program under grant agreement number 667387 WIDESPREAD 2-2014 SupraChem Lab.

\section{Disclosure}

The authors declare no potential conflicts of interest with respect to the research, authorship, and/or publication of this article.

\section{References}

1. Kovaleva J, Peters FT, van der Mei HC, Degener JE. Transmission of infection by flexible gastrointestinal endoscopy and bronchoscopy. Clin Microbiol Rev. 2013;26(2):231-254.

2. Schaefer MK, Jhung M, Dahl M, et al. Infection control assessment of ambulatory surgical centers. JAMA. 2010;303(22):2273-2279.

3. ANSI/AAMI ST58:2013. Chemical Sterilization and High-Level Disinfection in Health Care Facilities. Arlington, VA: Association for the Advancement of Medical Instrumentation; 2013.

4. Muscarella LF. Risk of transmission of cabapenem-resistant Enterobacteriaceae and related "superbugs" during gastrointestinal endoscopy. World J Gastrointest Endosc. 2014;6(10):457-474.

5. Humphries RM, McDonnell G. Superbugs on duodenoscopes: the challenge of cleaning and disinfection of reusable devices. JClin Microbiol. 2015;53:3118-3125.

6. McDonnell G, Sheard D. A Practical Guide to Decontamination in Healthcare. Oxford: Wiley-Blackwell; 2012.

7. Kim S, Muthusamy VR. Current practice of duodenoscope reprocessing. Curr Gastroenterol Rep. 2016;18(10):54-62.

8. Morrison JCF, inventor; Valleylab, Inc., Boulder, CO, assignee. Electrosurgical method and apparatus for initiating an electrical discharge in an inert gas flow. United States patent US 4040426. 1977 Aug 9.

9. Farin G, Grund KE. Technology of argon plasma coagulation with particular regard to endoscopic applications. Endosc Surg Allied Technol. 1994;2(2):71-77.

10. Deng X, Shi JJ, Kong MG. Protein destruction by a helium atmospheric pressure glow discharge: capability and mechanisms. J Appl Phys. 2007;101:074701.

11. Fridman G, Peddinghaus M, Balasubramanian M, Ayan H, Fridman A, Gutsol A. Blood coagulation and living tissue sterilization by floatingelectrode dielectric barrier discharge in air barrier. Plasma Chem Plasma Process. 2006;26(4):425-442.

12. Deilmann M, Halfmann H, Bibinov N, Wunderlich J, Awakowicz P. Low pressure microwave plasma sterilization of polyethylene terephthalate bottles. J Food Prot. 2008;71(10):2119-2123.

13. Lerouge S, Wertheimer MR, Yahia LH. Plasma sterilization: a review of parameters, mechanisms, and limitations. Plasma Polym. 2001;6(3):175-188.

14. Moisan M, Barbeau J, Moreau S, Pelletier J, Tabrizian M, Yahia LH. Low temperature sterilization using gas plasmas: a review of the experiments and an analysis of the inactivation mechanisms. Int $J$ Pharm. 2001;226(1-2):1-21. 
15. Sladek RE, Stoffels E. Deactivation of Escherichia coli by the plasma needle. J Phys D Appl Phys. 2005;38:1716-1721.

16. Ursache M, Moraru R, Hnatiuc E, Nastase V, Mares M. Comparative assessment of the relation between energy consumption and bacterial burden reduction using plasma activated water. International Conference on Optimization of Electrical and Electronic Equipment (OPTIM); May 22-24, 2014; Moeciu de Sus, Bran (Romania), volume CFP1422DART: 1036-1041.

17. Marques MRC, Loebenberg R, Almukainzi M. Simulated biological fluids with possible application in dissolution testing. Dissolut Technol. 2011;18(3):15-28.

18. Petersen JH, Koch J, Ginsberg GG. Infection using ERCP endoscopes. Gastroenterology. 2016;151(1): 46-50.

19. Andriulli A, Loperfido S, Napolitano G, et al. Incidence rates of postERCP complications: a systematic survey of prospective studies. $\mathrm{Am}$ J Gastroenterol. 2007;102(8):1781-1788.

20. Hnatiuc E. Procedes bases sur les décharges electriques [Basic methods of electrical discharges]. In: Hnatiuc E, editor. Procedes Electrique de Mesure et de Traitement des Polluants. Paris: Tech \& Doc; 2002;219-291.

21. Jawad A, Heritage J, Snelling AM, Gascoyne-Binzi DM, Hawkey PM. Influence of relative humidity and suspending menstrua of survival of Acinetobacter spp. on dry surfaces. J Clin Microbiol. 1996;34(12): 2881-2887.

22. Williams AP, Avery LM, Kilham K, Jones DL. Persistence of Escherichia coli $\mathrm{O} 157$ on farm surfaces under different environmental conditions. J Appl Microbiol. 2005;98(5):1075-1083.

23. Kramer A, Schwebke I, Kampf G. How long do nosocomial pathogens persist on inanimate surfaces? BMC Infect Dis. 2006;6:130.

24. Neely AN. A survey of gram-negative bacteria survival on hospital fabrics and plastics. J Burn Care Rehabil. 2000;21(6):523-527.

25. Moses FM, Lee J. Surveillance cultures to monitor quality of gastrointestinal endoscope reprocessing. Am J Gastroenterol. 2003;98(1):77-81.

26. Martiny H, Floss H, Zühlsdorf B. The importance of cleaning for the overall results of processing duodenoscopes. J Hosp Infect. 2004;56(2):S16-S22.

27. Schenk J, Riemann JF, Gräf W. Bacteriological efficiency of a standardized cleansing and disinfection technique for duodenoscopes. Endoscopy. 1978;10(2):75-79.
28. Singh S, Singh N, Kochhar R, Mehta SK, Talwar P. Contamination of an endoscope due to Trichosporon beigelii. J Hosp Infect. 1989;14:49-53.

29. Petersen JH, Weesner RE, Gianella RA. Escherichia coli peritonitis after left-sided endoscopy in a patient on continuous ambulatory peritoneal dialysis. Am J Gastroenterol. 1981;82:171-172.

30. Ross AS, Baliga C, Verma P, Duchin J, Gluck M. A quarantine process for resolution of duodenoscope-associated transmission of multi-drug resistant Escherichia coli. Gastrointest Endosc. 2015;82(3):477-483.

31. Aumeran C, Poindoux L, Souweine B, et al. Multidrug-resistant Klebsiella pneumoniae outbreak after endoscopic retrograde cholangiopancreatography. Endoscopy. 2010;42(11):895-898.

32. McCool S, Clarke L, Querry A, et al. Carbapenem-resistant enterobacteriaceae (CRE) Klebsiella pneumonia (KP) cluster analysis associated with GI duodenoscopes with elevator channel. In: ID Week; October 2-6, 2013; San Francisco. Abstract 1619.

33. Epstein L, Hunter JC, Arwady MA, et al. New-Delhi metallo- $\beta$-lactamase producing carbapenem-resistant Escherichia coli associated with exposure to duodenoscopes. JAMA. 2014;312(14):1447-1455.

34. Smith ZL, Oh YS, Saeian K, et al. Transmission of carbapenem-resistant Enterobacteriaceae during ERCP: time to revisit the current reprocessing guidelines. Gastrointest Endosc. 2015;81(4):1041-1045.

35. McCarthy M. Meticulous cleaning of duodenoscopes may not eliminate infection risk, US watchdog warns. BMJ. 2015;350:h997.

36. Van der Bij AK, Van der Zwan D, Periano G, et al. Metallo-b-lactamase producing Pseudomonas aeruginosa in the Netherlands: the nationwide emergence of a single sequence type. Clin Microbiol Infect. 2012;18(9): E369-E372.

37. Naryzhny I, Silas D, Chi K. Impact of ethylene oxide gas sterilization of duodenoscopes after a carbapenem-resistant Enterobacteriaceae outbreak. Gastrointest Endosc. 2016;84(2):259-262.

38. Shoop NM. Flexible endoscopes: structure and function. The mechanical system. Gastroenterol Nurs. 2001;24(6):294-297.

39. Hayakawa S, Ueki K, inventors; US Patent and Trademark Office, assignee. Flexible tube for endoscope, material used for producing outer cover of the flexible tube, and production method of the flexible tube United States patent US 6599239 B2. 2003 Jul 29.

40. Balan GG, Pavel L, Sandu AV, Stefanescu G, Trifan AC. Preliminary study on erosion of polymer coatings of duodenoscopes. Rev Mater Plast. 2016;53(4): 791-795.
Infection and Drug Resistance

\section{Publish your work in this journal}

Infection and Drug Resistance is an international, peer-reviewed openaccess journal that focuses on the optimal treatment of infection (bacterial, fungal and viral) and the development and institution of preventive strategies to minimize the development and spread of resistance. The journal is specifically concerned with the epidemiology of antibiotic

\section{Dovepress}

resistance and the mechanisms of resistance development and diffusion in both hospitals and the community. The manuscript management system is completely online and includes a very quick and fair peerreview system, which is all easy to use. Visit http://www.dovepress.com/ testimonials.php to read real quotes from published authors. 